\title{
Sinergismo entre herbicidas no controle da corda-de-viola (Ipomoea Grandifolia) em pós-emergência
}

Synergism between herbicides in the control of the viola rope (Ipomoea Grandifolia) in postemergence

Sinergismo entre herbicidas en el control de la cuerda de viola (Ipomoea Grandifolia) en postemergencia

\section{Resumo}

Devido à capacidade de germinar, crescer e reproduzir-se em condições contrárias, como em situações de déficit hídrico, salinidade, solos ácidos ou alcalinos e temperaturas pouco propícias, as plantas daninhas tem sido um dos problemas fitossanitários mais difíceis de serem controladas nas áreas agrícolas, podendo resultar em prejuízos que podem chegar a altos níveis de perdas da lavoura. Objetivou-se com esse estudo avaliar a eficiência da aplicação isolada de Glyphosate, e associado aos herbicidas Chlorimuron, Imazethapyr, Lactofen e Flumioxazin no controle da Ipomoea grandifoli. Para isso, foi conduzido um experimento na casa de vegetação do campo experimental do UNIVAG - Centro Universitário de Várzea Grande. O delineamento experimental adotado foi o de blocos casualizados, com seis tratamento (Glifosato, Glifosato + Imazethapyr, Glifosato + Clorimoron, Glifosato + Flumioxazin, Glifosato + Lactofen e testemunha) e quatro repetições totalizando 24parcelas. Para determinação dos resultados, foram realizadas avaliações de fitointoxicação com base em uma escala visual de notas aos 7, 14 e 21 dias após a aplicação. Entre os herbicidas testados, os tratamentos com Glifosato + Flumioxazin e Glifosato + Lactofen produzirem o melhor resultado ( $100 \%$ de controle), já os tratamentos utilizando Glifosato isolado, Glifosato + Imezethapyr e Glifosato + Clorimuron demonstraram controle inferior para controlar a corda-de-viola.

Palavras-chave: Controle químico; Glyphosate; Manejo de plantas daninhas; Sinergismo.

\begin{abstract}
Due to the ability to germinate, grow and reproduce under adverse conditions, such as in situations of water deficit, salinity, acidic or alkaline soils and unsuitable temperatures, weeds have been one of the most difficult phytosanitary problems to be controlled in agricultural areas, which can result in damages that can reach high levels of crop losses. The aim of this study was to evaluate the efficiency of isolated application of Glyphosate, and associated with the herbicides Chlorimuron, Imazethapyr, Lactofen and Flumioxazin in the control of Ipomoea grandifoli. For this, an experiment was carried out in the greenhouse of the experimental field at UNIVAG - Centro Universitário de Várzea Grande. The experimental design adopted was a randomized block, with six treatments (Glyphosate, Glyphosate + Imazethapyr, Glyphosate + Clorimoron, Glyphosate + Flumioxazin, Glyphosate + Lactofen and control) and four replications totaling 24 plots. To determine the results, phytotoxicity evaluations were carried out based on a visual scale of notes at 7, 14 and 21 days after application. Among the herbicides tested, the treatments with Glyphosate +
\end{abstract}


Flumioxazin and Glyphosate + Lactofen produced the best result (100\% control), whereas the treatments using Glyphosate alone, Glyphosate + Imezethapyr and Glyphosate + Clorimuron showed inferior control to control the viola string.

Keywords: Chemical control; Glyphosate; Weed management; Synergism.

\section{Resumen}

Debido a la capacidad de germinar, crecer y reproducirse en condiciones adversas, como en situaciones de déficit hídrico, salinidad, suelos ácidos o alcalinos y temperaturas inadecuadas, las malezas han sido uno de los problemas fitosanitarios más difíciles de controlar en áreas agrícolas, lo que puede resultar en daños que pueden alcanzar altos niveles de pérdida de cultivos. El objetivo de este estudio fue evaluar la eficiencia de la aplicación aislada de Glifosato, y asociado a los herbicidas Clorimuron, Imazethapyr, Lactofen y Flumioxazin en el control de Ipomoea grandifoli. Para ello, se llevó a cabo un experimento en el invernadero del campo experimental de UNIVAG - Centro Universitário de Várzea Grande. El diseño experimental adoptado fue un bloque al azar, con seis tratamientos (Glifosato, Glifosato + Imazethapyr, Glifosato + Clorimoron, Glifosato + Flumioxazina, Glifosato + Lactofeno y control) y cuatro repeticiones totalizando 24 parcelas. Para determinar los resultados se realizaron evaluaciones de fitotoxicidad en base a una escala visual de notas a los 7, 14 y 21 días después de la aplicación. Entre los herbicidas probados, los tratamientos con Glifosato + Flumioxazina y Glifosato + Lactofeno produjeron el mejor resultado (control 100\%), mientras que los tratamientos con Glifosato solo, Glifosato + Imezethapyr y Glifosato + Clorimuron mostraron un control inferior para el control de las cuerdas.

Palabras clave: Control químico; Glifosato; Manejo de malezas; Sinergismo.

\section{Introdução}

Com o surgimento de várias espécies de plantas daninhas nos últimos anos, os produtores vêm buscando alternativas que possam reduzir essas infestações. Eles são, um dos mais difíceis problemas fitossanitários de serem controladas nas áreas agrícolas. Se não contidas, podem gerar diversos problemas sobre as culturas, como por exemplo a redução no rendimento e na qualidade dos produtos colhidos, resultando em prejuízos que podem inviabilizar a lavoura (Carneiro et al., 2020). As plantas daninhas mostram a capacidade de germinar, crescer e reproduzir-se em condições adversa às plantas cultivadas, como em situações de déficit hídrico, salinidade, solos ácidos ou alcalinos e temperaturas inadequadas (Agostineto et al., 2016).

AIpomoea grandifolia, popularmente conhecida como corda-de-viola, pertence à família Concolvulaceae, se destaca como uma das plantas daninhas mais problemáticas em lavouras agrícolas no Brasil (Carneiro et al., 2020) pois compete por recursos naturais (água, luz e nutrientes) e interferem na colheita, devido o hábito de crescimento entrelaçado (volúvel com hastes flexíveis), comprometendo o rendimento e eficiência das máquinas colhedoras (Silva et al., 2015).

A corda-de-viola apresenta comprimento entre um a dois metros na fase adulta, possui reprodução por sementes, sendo esse um dos fatores que dificultam seu controle, devido as sementes serem fisicamente dormentes, podendo permanecer viáveis no solo por vários anos (Carneiro et al., 2020). Suas folhas possuem grande variabilidade no formato, flores vistosas e intensamente coloridas, com raízes na maioria das vezes pivotantes (Lorenzi et al., 2014).

Dentre os métodos de controle, o químico é o mais utilizado na agricultura, sendo, o método de melhor eficácia. No entanto, seu uso indiscriminado e demasiado vem gerando crescente resistência de pragas, microrganismos fitopatogênicos e até mesmo resistência das próprias plantas daninhas aos produtos químicos, o que ocasiona maior dependência desses insumos por parte de produtores, resultado de uma visão equivocada do processo agrícola (Schutte et al., 2014).

Existe um número considerável de herbicidas registrados para o controle de corda-de-viola, como por exemplo, o glyphosate, que é inibidor da enzima 5-enol-piruvato-chiquimato-3-fosfato sintase (EPSPs), que tem como ingrediente ativo o $\mathrm{N}$-(fosfonometil) glicina (glyphosate) (Carneiro et al., 2020.

O glyphosate, apesar de ser um herbicida de ação total, deve ser utilizado apenas em pós-emergência inicial da cordade-viola, pois apresenta menor eficácia quando as plantas estão em estádio mais avançados de crescimento (Agostineto et al., 2016). 
Sabe-se que espécies deste gênero são tolerantes ao herbicida glyphosate, uma alternativa é buscar métodos para o controle dessas plantas invasoras (Agostineto et al., 2016). A mistura de herbicidas pode ser interessante e proporcionar melhor controle desta planta daninha, como por exemplo a mistura de glyphosate com PROTOX, ACCase e FSI (Ansolin et al. 2015).

A utilização simultânea ou sequencial de dois ou mais herbicidas sobre uma mesma cultura pode resultar em sinergismo. É uma importante estratégia de controle sobre as plantas daninhas, reduzindo a resistência dessas plantas com o uso de misturas de herbicidas ou rotação de herbicidas com diferente mecanismo de ação. A utilização de misturas que apresentam sinergismo permite o uso de doses menores e consequentemente o controle de plantas tolerantes (Bidóia, 2019).

Alpomoea grandifolia, apresenta uma tolerância devido à menor translocação do herbicida, não havendo evidências de metabolismo diferencial do herbicida por estar planta daninha. Estes resultados confirmam, para o efetivo controle destas plantas daninhas, a associação com outros herbicidas pode ser uma alternativa importante para o seu controle (Carneiro et al., 2020).

O objetivou-se com o trabalho avaliar a eficiência da aplicação isolada de Glyphosate, e associado aos herbicidas Chlorimuron, Imazethapyr, Lactofen, e Flumioxazin no controle da Ipomoea grandifolia.

\section{Metodologia}

O presente estudo utilizou-se de um método quali-quantitativo no qual através de uma escala visual foi observado quais herbicidas isolados ou não controlava a incidência da Ipomoea grandifolia (Carvalho, 2009).

O experimento foi desenvolvido na casa de vegetação do campo experimental do UNIVAG - Centro Universitário de Várzea Grande, município de Várzea Grande, Estado de Mato Grosso, cujas coordenadas $15^{\circ} 40^{\prime} 40,51^{\prime}$ ' S de Latitude e $56^{\circ}$ 06' 04” W de Longitude, aos 182 metros de altitude, durante os meses de setembro a dezembro de 2016.

Como unidade experimental foram utilizados vasos plásticos com capacidade de aproximadamente 5 litros. O delineamento experimental adotado foi o de blocos casualizados, com seis tratamentos e quatro repetições, totalizando 24 parcelas. Os tratamentos foram constituídos por: (T1) Glifosato, (T2) Glifosato + Imazethapyr, (T3) Glifosato + Clorimoron, (T4) Glifosato + Flumioxazin, (T5) Glifosato + Lactofen, (T6), e Testemunha, com as respectivas dosagens conforme as recomendações de Lorenzi et al. (2014) na Tabela 1.

Tabela 1. Tratamentos utilizados para controle da Ipomoea grandifolia, em experimento realizado em vasos, na casa de vegetação do campo experimental do UNIVAG - Centro Universitário de Várzea Grande, município de Várzea Grande, Estado de Mato Grosso, de setembro a dezembro de 2016. * $50 \mathrm{~g} \mathrm{ha}^{-1}$

Tratamentos Doses $\left(\mathrm{L} \mathrm{ha}^{-1}\right)$

Glifosato

$$
\begin{aligned}
& \text { Glifosato + Imazethapyr } \\
& \text { Glifosato + Clorimuron } \\
& \text { Glifosato + Flumioxazin* }
\end{aligned}
$$$$
\text { Glifosato + Lactofen }
$$

Testemunha

\section{2,5}

$2,5+0,7$

$$
2,5+40
$$

$2,5+50$

$2,5+0,4$ 
Os tratamentos T3 e T4 tiveram a adição de $0,5 \%$ v/v de Nimbus, para melhor absorção, devido sua formulação. O solo utilizado foi retirado da camada de $0-20 \mathrm{~cm}$ do solo do local, sendo classificado como latossolo, cujas amostras foram realizadas as caracterizações química e granulométrica (Tabela 2), conforme os métodos descritos pela EMBRAPA (1997).

Tabela 2. Caracterização química e granulométrica da camada de $0-20 \mathrm{~cm}$ de um latossolo, utilizada em experimento realizado em vasos, na casa de vegetação do campo experimental do UNIVAG - Centro Universitário de Várzea Grande, município de Várzea Grande, Estado de Mato Grosso, de setembro a dezembro de 2016, para controle da Ipomoea grandifolia.

\begin{tabular}{|c|c|c|c|c|c|c|c|c|c|c|c|}
\hline $\mathrm{pH}$ & $\mathrm{pH}$ & $\mathrm{P}$ & $\mathrm{K}$ & $\mathrm{Ca}$ & $\mathrm{Mg}$ & $\mathrm{Al}$ & $\mathrm{H}$ & M.O & Areia & Silte & Argila \\
\hline $\mathrm{H}_{2} \mathrm{O}$ & $\mathrm{CaCl}_{2}$ & $\mathrm{mg} \mathrm{dm}^{-3}$ & & lc dm ${ }^{-3}$ & & $\mathrm{~g} \mathrm{dm}^{-3}$ & & $\mathrm{~g} \mathrm{dm}^{-3}$ & & $\mathrm{~g} \mathrm{~kg}^{-1}$ & \\
\hline 5,50 & 4,80 & 0,60 & 17,00 & 2,81 & 0,35 & 0,06 & 5,44 & 34,00 & 107,00 & 123,00 & 770,00 \\
\hline
\end{tabular}

Fonte: Autores (2016).

Antes da semeadura foi realizado a adubação conforme análise de solo. Foram semeadas 15 sementes por vaso, em uma profundidade de $3 \mathrm{~cm}$. Após a germinação foi realizado o desbaste, permanecendo duas plantas por vaso. Os vasos foram verificados diariamente para a retirada de outras ervas daninhas e aparecimento de doenças nas plantas, recebendo irrigação de aproximadamente $5 \mathrm{~L} \mathrm{~d}^{-1}$.

As aplicações dos herbicidas nos tratamentos foram realizadas após atingirem em média 9 folhas por planta e $30 \mathrm{~cm}$ de comprimento aproximadamente. Para aplicação dos herbicidas foi utilizado um pulverizador costal manual, pressurizado por $\mathrm{CO}^{2}$, com uma barra de 3 metros, com bicos tipo leque JSF 11002, espaçados a 0,5 metros, com o qual se aplicou um volume de calda correspondente a 160 litros ha ${ }^{-1}$.

O percentual de controle (\%) foi avaliado aos 7, 14 e 21 dias após a aplicação (DAA), quando foi adotada uma escala visual de notas utilizou 0 como ausência de sintomas e 100 como a morte de todas as plantas Segundo Carvalho, 2009.

Os dados obtidos foram submetidos a análise de variância ao nível de $5 \%$ de significância e as médias dos tratamentos foram comparadas pelo Teste de Tukey $(p>0,05)$ utilizando o programa estatístico SISVAR (Ferreira, 2011).

\section{Resultados e Discussão}

Com base nos dados obtidos sobre o controle percentual de corda-de-viola, aos 7 dias após a aplicação (DAA), notase que os melhores resultados de controle foram obtidos quando se utilizou o herbicida flumioxazin e o lactofen em mistura com o glifosato. Os tratamentos que receberam a adição de outros herbicidas (glifosato, imezethapyr+glifosato e clorimuron+glifosato) utilizou 0 como ausência de sintomas e 100 como a morte de todas as plantas (Tabela 3).

Aos 14 dias após a aplicação, observou-se que os tratamentos em que foi utilizado o flumioxazin e o lactofen em mistura com o glifosato $2,5 \mathrm{~L} \mathrm{ha}^{-1}+50 \mathrm{~g} \mathrm{ha}^{-1}$ e 2,5 $+0,4 \mathrm{~L} \mathrm{ha}^{-1}$ foram os únicos que expressaram resultados significativamente superior aos demais tratamento. Enquanto os tratamentos em que foram utilizados glifosato, imezethapyr+glifosato e clorimuron+glifosato, apresentaram controle inferior a 43\%, foram superiores à testemunha e não resultaram em diferenças significativas entre si.

O melhor nível de controle aos 21 dias após aplicação, se deu pela mistura de glifosato+flumioxazin e glifosato+lactofen mantendo $100 \%$ de controle. Os demais tratamentos apresentaram controle inferior a $54 \%$, foram estatisticamente superiores à testemunha, mas não diferiram estatisticamente entre si 
Todavia, no tratamento com glifosato isolado e a testemunha, foram observados maior quantidade de plantas daninhas e com porte elevado em comparação os demais tratamentos.

Tabela 3. Controle de Ipomoea grandifolia, em experimento realizado em vasos, na casa de vegetação do campo experimental do UNIVAG - Centro Universitário de Várzea Grande, município de Várzea Grande, Estado de Mato Grosso, de setembro a dezembro de 2016.

\begin{tabular}{|c|c|c|c|}
\hline Tratamentos & 7 DAA & 14 DAA & 21 DAA \\
\hline Glifosato & $16.25 \mathrm{~b}$ & $20.00 \mathrm{~b}$ & $31.25 \mathrm{~b}$ \\
\hline Glifosato + Imezethapyr & $10.00 \mathrm{~b}$ & $28.75 \mathrm{~b}$ & $48.75 \mathrm{~b}$ \\
\hline Glifosato + Clorimuron & $18.75 \mathrm{~b}$ & $42.50 \mathrm{~b}$ & $53.75 \mathrm{~b}$ \\
\hline Glifosato + Flumioxazin & $100.00 \mathrm{a}$ & $100.00 \mathrm{a}$ & $100.00 \mathrm{a}$ \\
\hline Glifosato + Lactofen & $90.00 \mathrm{a}$ & $100.00 \mathrm{a}$ & $100.00 \mathrm{a}$ \\
\hline Testemunha & $0.00 \mathrm{c}$ & $0.00 \mathrm{c}$ & $0.00 \mathrm{c}$ \\
\hline $\mathrm{CV} \%$ & 16.64 & 34.91 & 31.92 \\
\hline
\end{tabular}

Médias seguidas de mesma letra minúscula na linha, não diferenciam entre si pelo teste de Tukey a 5\% de probabilidade. Fonte: Autores (2016).

Takano et al. (2020) verificaram que a combinação de inibidores da EPSPS e da PROTOX, em seu estudo, gerou melhores resultados quando comparado com os produtos aplicados de forma isolada, sendo assim, a combinação destes herbicidas proporcionou melhor controle das plantas daninhas no campo e pode ajudar a superar os efeitos negativos das condições ambientais pela ação dos herbicidas. Corroborando com o estudo realizado, onde foi visto, melhor controle da corda-de-viola utilizando o flumioxazin e o lactofen em mistura com o glifosato.

Andrade Júnior et al. (2012), utilizaram aplicação de glufosinato de amônio para controlar a corda-de-viola e o leiteiro. Aos 14 dias após a aplicação, os níveis de controle obtidos oscilaram entre 90 e 100\%, mas não obtiveram diferença entre as doses utilizadas. No entanto, no presente estudo a aplicação desse herbicida apresentou $20 \%$ de controle, diferindo dos melhores tratamentos, provavelmente porque as plantas invasoras estão se tornando tolerando ao glifosato.

Em relação a esse herbicida, outros trabalhos também demonstram a ineficiência de controle em doses de até $1.920 \mathrm{~g}$ e.a./ha. (Ramires et al., 2010; Souza et al., 2013; Agostineto et al., 2016). Esta ineficácia é ocasionada por mecanismos de tolerância da corda-de-viola como absorção e translocação diferencial. A absorção e a translocação, se tiverem alterações, afetam a quantidade de glifosato que chega ao local de ação, não sendo o suficiente para o controle (Carneiro et al., 2020).

Outros métodos que influenciam a eficiência é o mecanismo de metabolização do glifosato em outras substâncias, como compostos inativos ou com menores níveis tóxicos, como o ácido aminometilfosfônico, glioxalato e sarcosina, além da compartimentalização com a retenção das moléculas nos vacúolos (Agostineto et al., 2016). Ribeiro et al. (2015) verificaram que a tolerância da Ipomoea lacunosa L. ao inibidor da EPSPS é principalmente pela translocação diferencial.

Os dados obtidos no presente estudo, enfatizam o estudo de Presoto et al., (2020), que relataram que, quando o controle obtido for maior que o esperado, acontece sinergismo, o que ocorreu, no presente estudo com os tratamentos de 
flumioxazin e o lactofen em mistura com o glifosato, onde não se observou o antagonismo dos herbicidas quando associados com glifosato.

Carneiro et al. (2020) evidencia que o inibidor da EPSPS, seria o melhor tratamento para o controle da corda-de-viola, no entanto, Agostineto et al. (2016) demonstrou que o glifosato só é eficiente para essa planta daninha, quando apresenta estádio fenológico pós-inicial, corroborando com os dados obtidos no presente estudo, onde os tratamentos que foram aplicados em plantas com estádio fenológico pós-tardio (aproximadamente nove folhas), não demostraram eficiência no controle.

Carvalho e Gonçalves Netto (2016), salientam que para um controle eficaz com o glifosato, deve-se utilizar a associação com outros herbicidas, reafirmando o que foi visto no presente estudo, sendo uma alternativa para o controle no campo, onde é possível controlar plantas tolerantes ao glifosato quando associados com herbicidas inibidores da PROTOX.

\section{Conclusão}

Entre os herbicidas testados, pode-se concluir que os tratamentos de Glifosato + Flumioxazin e Glifosato + Lactofen obtiveram o melhor resultado (100\% de controle), já os tratamentos utilizando Glifosato isolado, Glifosato + Imazethapyr e Glifosato + Chlorimuron demonstraram controle inferior a corda-de-viola.

Para novos experimentos sugerimos que se faça a campo, pois evidencia a realizada no campo. Assim, esses novos estudos devem ser estimulados com o objetivo de avaliar mais opções para elevar ainda mais a eficácias dos tratamentos.

\section{Referências}

Agostineto, M. C. et al. (2016). Sinergismo de misturas de glyphosate e herbicidas inibidores da PROTOX no controle de corda-de-viola. Revista de Ciências Agroveterinárias, 15 (1), 8-15.

Andrade Junior, E. R. et al. (2012) Controle de corda-de-viola (Ipomoea triloba) e leiteiro (Euphorbia heterophylla), na cultivar de algodoeiro IMA CD 6001 LL com o herbicida glufosinato de amônio. In: Congresso Brasileiro de Algodão, 8., 2012, Campina Grande, PB. Anais... Campina Grande: Embrapa Algodão. 788-796.

Bidóia, V. S. Estratégias de manejo químico para controle de mucuna aterrima, ricinus communis, merremia aegyptia, ipomoea hederifolia e ipomoea quamoclit e sua seletividade no plantio da cana-de-açúcar. 2019. 72p. Dissertação (Mestrado) - Universidade Estadual Paulista (Unesp), Jaboticabal.

Carneiro, G. D. O. P. et al. (2020). Eficácia de herbicidas no controle pós-emergência de corda-de-viola. Revista Brasileira de Herbicidas. 19 (2), 1-6.

Carvalho, S. J. P. Dessecação de plantas daninhas com o herbicida glyphosate associado a fertilizantes nitrogenados. 2009. 116p. Tese (Doutorado) - Escola superior de agricultura Luiz Queiroz, ESALQ/USP. Piracicaba.

Carvalho, S. J. P. Gonçalves Netto, A. (2016). Resistência de plantas daninhas aos herbicidas inibidores da PROTOX (Grupo E). In.: Christoffoleti, P.J.; Nicolai, M. (Coord.). Aspectos de resistência de plantas daninhas a herbicidas. ESALQ. 151-175.

Castro, E. B. et al. (2017). Deposição da calda e eficácia de controle de glyphosate e saflufenacil associados a adjuvantes. Revista Brasileira de Herbicidas. $16(2), 103-111$.

EMBRAPA. (1997). Manual de métodos de análises de solo. Centro Nacional de Levantamento e Conservação do Solo. Embrapa Solos.

Ferreira, D. F. (2008). SISVAR: um programa para análises e ensino de estatística. Revista Symposium, 6 (2), 36-41.

Goncalves, C. G. et al. (2016). Selectivity of saflufenacil applied singly and in combination with glyphosate on coffee and citrus crops. Revista Caatinga. 29 (1), 45-53.

Kissmann, K. G.; \& Groth, G. (1999). Plantas infestantes e nocivas. Tomo II. (2a ed.), BASF.

Lorenzi, H. et al. (2014). Manual de identificação e controle de plantas daninhas. (7a ed.), Plantarum.

Presoto; J. C.; Andrade, J. F.; \& Carvalho, J. P. C. (2020). Interação e eficácia de misturas em tanque dos herbicidas saflufenacil e glyphosate. Revista Brasileira de Herbicidas. 19 (4).

Ramires, A. C. et al. (2010). Controle de Euphorbia heterophylla e Ipomoea grandifolia com a utilização de glyphosate isolado ou em associação com latifolicidas. Planta daninha. 28 (3), 621-629.

Ribeiro, D. N. et al. (2015). Possible glyphosate tolerance mechanism in pitted morningglory (Ipomoea lacunosa L.). Journal of agricultural and food chemistry. 63 (6), 1689-1697. 
Research, Society and Development, v. 10, n. 12, e215101220429, 2021

(CC BY 4.0) | ISSN 2525-3409 | DOI: http://dx.doi.org/10.33448/rsd-v10i12.20429

Schutte, B. J. et al. (2017). Measuring interference from midseason tall morningglory (Ipomoea purpurea) to develop a model for teaching weed seedbank effects on chile pepper. Weed Technology. 31 (1), 155-164.

Silva, et al. (2015). Aplicação de herbicidas em pré-emergência sobre palha de cana-de-açúcar para o controle de espécie da família Convolvulaceae. Revista Agro@ambiente On-line.9(2), 184-193.

Souza, G. S. F.; Martins, D.; \& Pereira, M. R. R. (2013). Efeito da chuva na eficiência de herbicidas aplicados em pós emergência sobre corda-de-viola. Planta Daninha. 31 (1), 175-184.

Takano, H. et al. (2020). Glufosinate enhances the activity of protoporphyrinogen oxidase inhibitors. Weed Science. 35 (4), 324-332.

Vieira Júnior, N. S. et al. (2015). Associação de herbicidas aplicados em pós emergência na cultura do milho. Global Science and Technology. 8 (1), 1-8.

Zhao, F. et al. (2018). Individual and combined toxicity of atrazine, butachlor, halosulfuron-methyl and mesotrione on the microalga Selenastrum capricornutum. Ecotoxicology and Environmental Safety. 148, 969-975. 